\title{
A system dynamic investigation on Iranian electricity industry
}

\author{
Alireza Asadi and Raheleh Ghezelsoflo*
}

Iran Electrical Industry Syndicate, Education and Research Department, Tehran, Iran

\begin{tabular}{|c|c|}
\hline ART I C L E I N F O & A B S T R A C T \\
\hline $\begin{array}{l}\text { Article history: } \\
\text { Received April 19, } 2012 \\
\text { Accepted } 12 \text { June } 2012 \\
\text { Available online } \\
\text { June } 142012 \\
\text { Keywords: } \\
\text { System dynamics } \\
\text { Electricity industry } \\
\text { Productivity }\end{array}$ & $\begin{array}{l}\text { Management of energy plays an important role on having sustainable growth on the economy of } \\
\text { developing countries. Electricity is part of the main infrastructure of any country, it can help } \\
\text { develop many industries, and any shortage in electricity can jeopardize many heavy industries. } \\
\text { In Iran, for many years electricity used to be subsided by the government hoping that economy } \\
\text { grows faster but this caused a major problem for this industry since the electricity industry } \\
\text { could not handle its expenses and faced with somewhat irreversible crises. In this paper, we } \\
\text { present a system dynamic investigation to study the existing crises in this sector. The } \\
\text { preliminary result of the implementation of system dynamic is that the sector needs to increase } \\
\text { its productivity, significantly and lowers the cost of product. }\end{array}$ \\
\hline
\end{tabular}

\section{Introduction}

Electricity plays an important role in our lives and without electricity, it is nearly impossible to live with the same standard, internet facilities will become in accessible, telephones, mobiles will turn off and we face an unpleasant life. For many years, local governments of Iran was subsiding this industry in an attempt to help economy grow and to reduce the cost of living. Since this is a nationalized industry, government was responsible to cover the necessary budget requested by electricity industry. For many years, the costs of building new facilities for developing the industry as well as the cost of maintaining the existing infrastructures increased. The industry could not make on time payment of its expenses and there was a huge amount of debt accumulating on this industry. During the past few years, government has tried to increase its prices in different stages but the issue has remained unresolved since there are still huge liabilities surrounding the industry and it is not an easy task to get rid of the existing chaos, very easily.

\footnotetext{
* Corresponding author. Tel: +982188831994-6

E-mail addresses: ghezel@ieis.ir, (R. Ghezelsoflo)

(C) 2012 Growing Science Ltd. All rights reserved. doi: $10.5267 /$ j.msl.2012.06.018
} 
During the past few years, there have been many studies for electricity industry in the world. Kiani and Pourfakhraei (2010) presented a system dynamic, which considers the feedback between supply and demand and oil revenue of the existing system in Iran and by looking at various sectors of the economy. They considered the export of the oil surplus and the injection of the gas surplus into the oil reservoirs in the model by building a balance between supply and demand. In their proposed model, the counter-effects and existing system feedbacks between supply and demand and oil revenue considered various sectors of the economy. As a result, the effects of oil and gas regulations in various scenarios for different sectors of Iran's economy together with the counter-effects of energy consumption and oil revenue were investigated. They offered three scenarios, which show the worst, base and ideal cases to find future trends of major variables such as seasonal gas consumption in power plants, seasonal injected gas in oil reservoirs, economic growth in the industrial sector, oil consumption in the transportation sector, industrial gas consumption and exported gas. According to their research, the exported gas will reach between 500 and 620 million cubic-meter per day in various scenarios and export revenues can reach up to $\$ 500$ billion by 2025.

As we explained earlier, electricity distribution companies not only in Iran but also in many other countries are not profitable and one way to measure the relative efficiency of them is to use data envelopment analysis (DEA). In DEA, different similar units are compared based on different inputs and various outputs. Sadjadi and Omrani (2008) presented a model with uncertain data for performance assessment of electricity distribution firms. Their proposed method developed a new DEA method by considering uncertainty on output parameters.

System dynamic (SD) has been used among many practitioners for analyzing the cause and effects relationships, which exist in a system. Forrester (1969-1971) is believed to be the first who introduced the idea of SD for some urban investigations.

According to Ford (1996) system dynamics methodology has been widely used for different applications in the electric power industry. System dynamics is able to provide us a unique capability to "see the feedback" at work in the power system. There are many studies contributed to useful change in the power industry, and it is possible to build a record on water resource systems. In addition, whenever we have come across to a "see the feedback" at work in any field, system dynamics will create the opportunity to contribute in a unique manner.

Ghaffarzadegan et al. (2011) explained that public policies often could not achieve their intended result because of the complexity of both the environment and the policy-making process. They reviewed the advantages of using small SD models to address public policy questions. They first discussed the main issues inherent in the public policy-making process and next they explained how small system dynamics models could address policy-making difficulties by addressing two promising instances where the first one was associated with the domain of urban planning and the second one was related in the domain of social welfare. The examples demonstrated how small models could yield accessible, insightful lessons for policy making stemming from the endogenous and aggregate perspective of SD modeling and simulation.

In this paper, we present a framework based on the implementation of SD to analyze the current status of electricity distribution companies in Iran. The organization of this paper first presents details of SD framework in section 2 and the findings based on the results are given in section 3 . Finally, we present concluding remarks to summarize the contribution of the paper.

\section{The proposed SD framework}

As we discussed earlier, there are different issues surrounding the electricity distribution firms in Iran such as huge amount of liabilities to their suppliers, lack of a good financial support from the government, etc. We have build a cause and effect relationship between some of the most important components in this system. Fig. 1 shows details of our proposed study. 


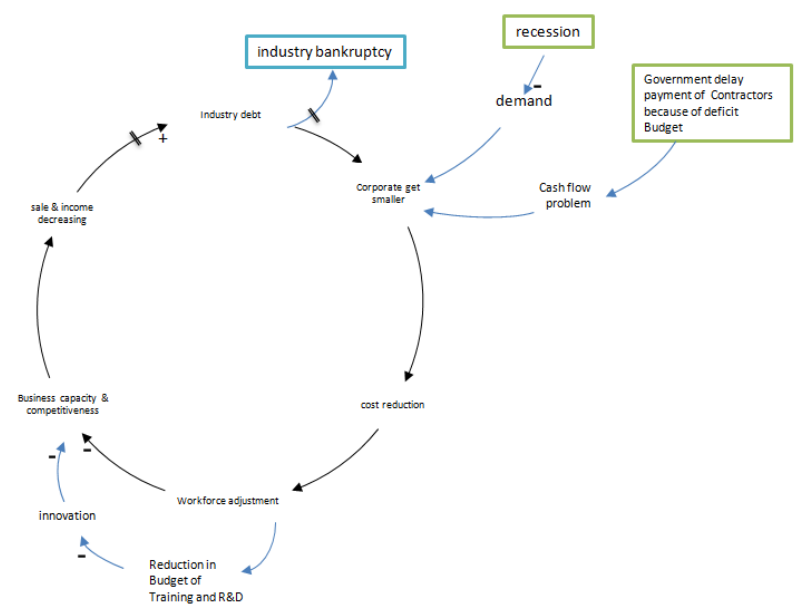

Fig. 1. The impact of economic crises on electricity industry

Fig. 1 shows the impact of economic crises on electricity industry. As we can observe from the figure, there is delay on government payment to industry, which creates cash flow problem. Another issue rises from economic recession where industry cannot pay its outstanding bills. Some of these industries file bankruptcy protection, which immunes them from any debt payment delay. There also other companies, which face with bankruptcy and close their sites and it is nearly impossible for hydro generation units to settle their invoices. On the other hand, the existing firms also lose their revenue because of economic turmoil and the remaining business units cut the number of their employees and try to reduce their expenses. According to a report published by Electrical Industry Syndicate of Iran in 2012, many industries worked only in 30\% of their working capacities and this could simply show the economic conditions. Vicious cycle of bankruptcy includes many barriers, which create trouble in this industry. These factors are summarized in Fig 2.

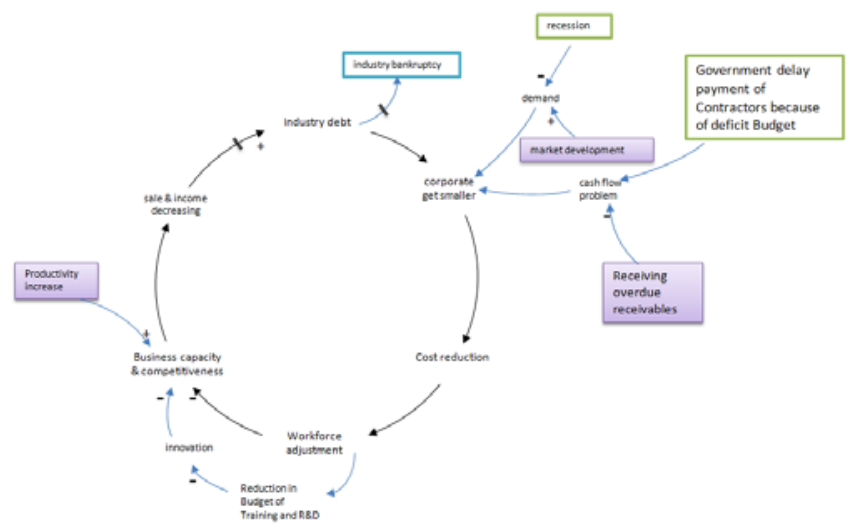

Fig. 2. Barriers for developing electricity units

One of the important factors in contributing the cycle is reduction in demand in national level and this could be improved through introducing new regulations and improving market. Developing export, creativity and innovation are among the most important factors, which could improve economy. Recently, many business units are changing their focus towards new sources of energies, which are also environment friendly and this could help overall market conditions.

Presently, government maintains over 6 billion dollars debt to electricity industry, which is one of the most challenging issues in this industry. As long as this debt exists between the government and electricity industry, the industry cannot pay its commitments to different suppliers and contractors. Many small contractors could go bankrupted once the payments are not paid on time. Therefore, an 
immediate solution for reducing any bad consequences is to encourage government to reduce the amount of financial commitments to electricity sector.

\section{Solution strategies}

In this section, we present some of the most important actions, which could help improve the current status of electricity units.

\subsection{Productivity improvement}

Based on shareholder value theory, the primary objective of any firm is to maximize the wealth of its shareholders. A firm do its best to maximize the return to shareholders, as measured by the sum of capital gains and dividends, for a given level of risk or attempt to reduce the risk associated with the same level of income. According to Kaplan and Norton (1996, 2000, 2004) business units normally have two basic options to increase their shareholders' value: revenue growth and productivity. The former generally has two items: build the franchise with revenue from new products, new markets and new customers; and increase value to existing customers by deepening relationships with them by expanding the sales. The productivity strategy maintains two parts: improve the company's expenditure structure by reducing direct and indirect costs, and utilize assets more efficiently by reducing the working and fixed capital needed to help a given level of business. There are different ways on reducing the costs such as removing bottlenecks and reducing cash flow costs. In such circumstances, intangible assets such skilled human resources play important role on managing electricity firms. Intangible assets are the primary sources of learning and growth for many firms specially in electricity distribution industry.

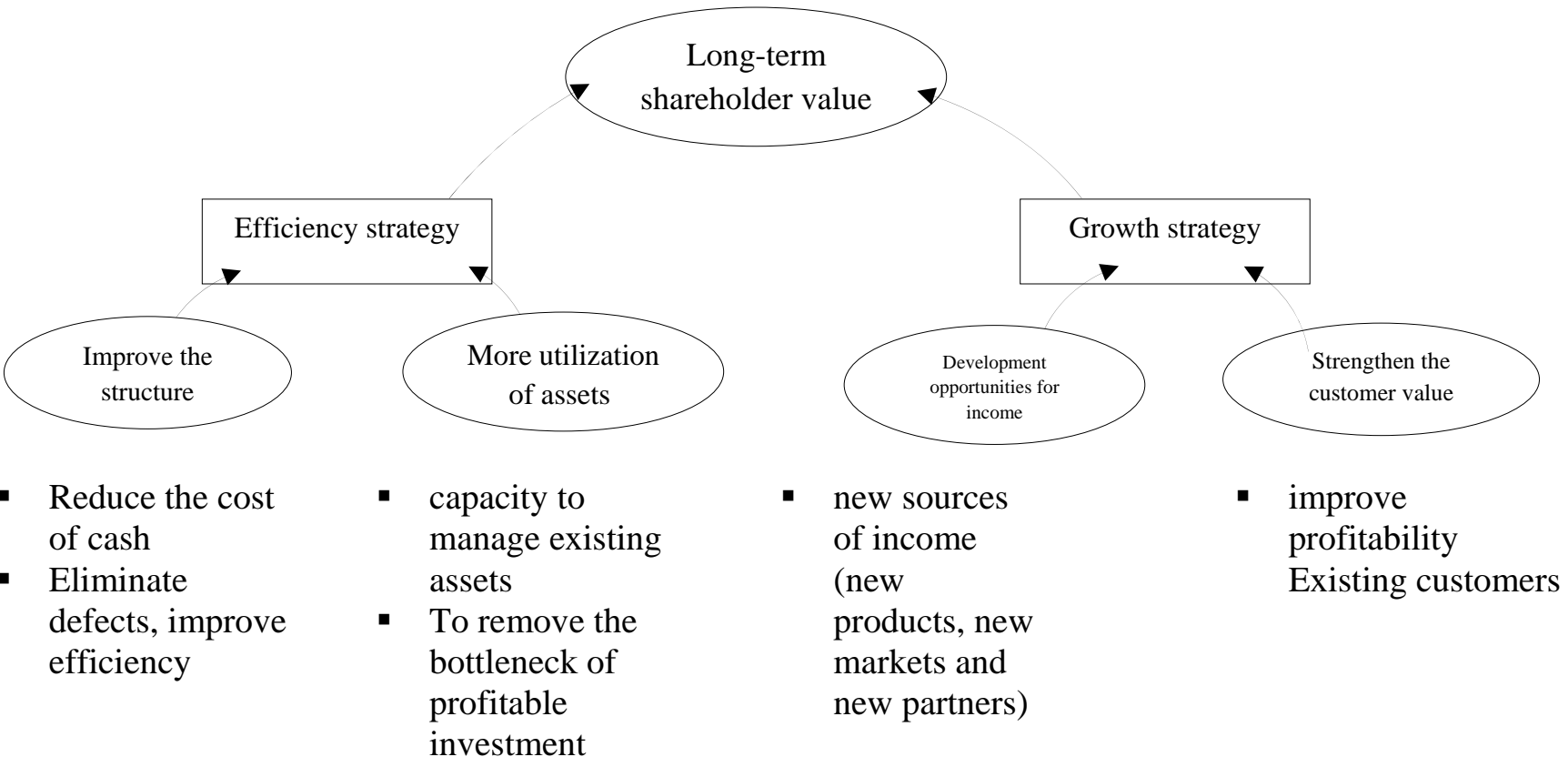

Fig. 3. Business strategy to strengthening business units

Fig. 4 shows details of our proposed framework for increasing productivity and human capital. 


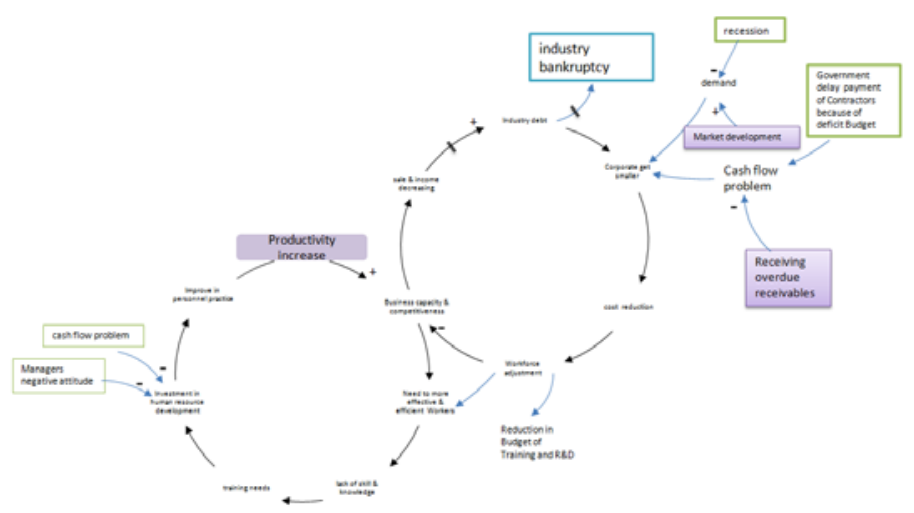

Fig. 4. The proposed framework for increasing productivity and human capital

\subsection{Training courses}

As we can observe from the figures, it is quite possible to increase productivity through better utilizing the resources and advances in information technology. According to the figure, one alternative solution is to reduce the number of inefficient and unskilled employees and increase the number of skilled and experienced employees. In other words, we need to fill in the existing gap created by inefficient workers by extending training courses either in terms of short-term or long-term plans. However, there are some limitations on having such training courses including lack of a good support from management team, lack of a good employees' educational background, lack of a good motivation to learn more among the existing employees, low level of income, unsuitable relationships between employees and their managements, inappropriate hiring strategies, etc. Note that it is always possible to find good educational system where it provides fair tuitions, high quality instructors with good teaching equipments.

Since 2011, the government of Iran has started a program to deregulate this industry so that consumers pay the cost of energy, completely. Although this could help this industry relive but still the cost of electricity is relatively high in Iran, which means the industry is inefficient and this inefficiency is about to move on consumers' shoulders. This simply shows that the suggested productivity program must be executed in this industry to reduce any unnecessary expenditures.

\section{Conclusion}

In this paper, we have presented an empirical investigation on electricity industry of Iran. The proposed model of this paper implemented a cause and effect diagram to investigate this industry. We have concluded that the best way to help this industry coming out of crises is to ask the government for a quick settlement of debts. We have also explained that despite the fact that government tries to deregulate this industry and lets them charge their consumer higher prices, but the cost of electricity is relatively high and productivity improvement must be carefully accomplished in this industry.

\section{Acknowledgment}

The authors would like to thank the officials of electricity industry for participating in our brain storming discussions. The authors are also grateful for constructive comments on earlier version of this paper.

\section{References}

Ford, A. (1996). System dynamics and the electric power industry. System Dynamics Review, 13(1), 57-85.

Forrester, J.W. (1969). Urban Dynamics. MIT Press: Cambridge, MA. 
Forrester, J.W. (1971). World Dynamics. Wright-Allen Press: Cambridge, MA.

Ghaffarzadegan, N., Lyneis, J., \& Richardson, G.P. (2011). How small system dynamics models can help the public policy process, System Dynamics Review, 27(1), 22-44.

Kaplan, R.S., \& Norton, D.P. (1996). Using the balanced scorecard as a strategic management system, Harvard Business Review, 75-85.

Kaplan, R.S., \& Norton, D.P. (2000). Strategy Focused Organizations, Harvard Business School Press, Boston, MA, 2000.

Kaplan, R.S., \& Norton, D.P. (2000). Having trouble with your strategy? Then map it, Harvard Business Review, 167-76.

Kiani, B., \& Pourfakhraei, M.A. (2010). A system dynamic model for production and consumption policy in Iran oil and gas sector. Energy Policy, 38(12), 7764-7774.

Sadjadi, S. J., \& Omrani, H. (2008). Data envelopment analysis with uncertain data: An application for Iranian electricity distribution companies. Energy Policy, 36, 4247-4254. 